\title{
A aprendizagem da história a partir da construção de narrativas sobre o passado
}

\author{
Marlene Cainelli ${ }^{1}$ \\ Isabel Barca²
}

\section{Resumo}

Esta investigação analisa a constituição do pensamento histórico de jovens estudantes entre 12 e 14 anos do ensino fundamental no Brasil e em Portugal, com relação aos fatos que se articulam nas histórias nacionais dos dois países. Os eventos escolhidos para o estudo em questão concentram-se em elementos relacionados ao conteúdo substantivo e à meta-história, no ensino de história do Brasil e história de Portugal. Analisamos, neste artigo, a forma como os alunos brasileiros e portugueses responderam ao desafio de pensar a história do Brasil sem a presença portuguesa. Nosso trabalho se fundamenta na ideia de que, para a constituição de aprendizagens históricas, é importante que os alunos sejam capazes de compreender as diversidades históricas do passado humano reconstituído pela historiografia. Isso implica na capacidade de produzir conhecimentos a partir da consciência de que o conhecimento sobre o passado é realizado perante a evidência histórica. Entre os resultados que encontramos está a forma tradicional de ensinar história que ainda vigora, principalmente nas escolas brasileiras: a falta de utilização de marcadores temporais pelos alunos brasileiros. Com relação à análise das narrativas, pudemos perceber, na maioria dos jovens, um entendimento do passado como estático, mas também encontramos narrativas que estabelecem uma relação entre presente, passado e futuro ao perspectivar a possibilidade de mudança do curso dos fatos.

\section{Palavras-chave}

Educação histórica - Pensamento histórico - Narrativa histórica.

1- Universidade Estadual de Londrina, Londrina, PR, Brasil.

Contato: cainelli@uel.br

2 - Universidade do Minho, Braga, Portugal.

Contato: isabarca@clix.pt 


\section{History learning based on the construction of narratives about the past}

\section{Abstract}

This research analyses the constitution of the historical thought of young students ages 12-14 from elementary schools in Brazil and Portugal, concerning facts articulated with the national histories of both countries. The events chosen for this research are focused on elements related to substantive content and meta-history in the teaching of the history of Brazil and the history of Portugal. We analyze, in this article, the way Brazilian and Portuguese students have answered to the challenge of thinking the history of Brazil without the Portuguese presence. Our work is based on the idea that, to build historical learning, it is important that students are capable to understand historical diversities from the human past reconstituted by historiography. This implies the capacity to produce knowledge understanding that the knowledge about the past is accomplished through historical evidence. Among the results we have found, it is the traditional way to teach History that still prevails, mainly in Brazilian schools: the lack of use of temporal markers by Brazilian students. Regarding the analysis of the narratives, we could notice, in most of the young students, an understanding of the past as something static, but we have also found narratives establishing relations between the present, past, and future, considering the possibility of changing the course of facts.

\section{Keywords}

History Education - Historical thought - Historical narrative.

\section{Introdução}

Nosso trabalho se fundamenta na ideia de que, para a constituição de aprendizagens históricas, é importante que os alunos sejam capazes de compreender as diversidades históricas do passado humano reconstituído pela historiografia. Isso implica na capacidade de produzir conhecimentos a partir da consciência de que o entendimento sobre o passado é realizado com base na evidência histórica. Esta investigação tem como suporte teórico e metodológico os pressupostos da investigação em educação histórica, no sentido de que a forma como os indivíduos mobilizam os conhecimentos históricos e constroem a sua consciência histórica conferem sentido à história e a eles próprios. 
Neste estudo, discutimos a constituição do pensamento histórico de jovens estudantes do ensino fundamental no Brasil e em Portugal com relação aos acontecimentos que se articulam nas histórias nacionais dos dois países. ${ }^{3}$ Tendo como referência a afirmativa de Collingwood (1978) de que o pensamento histórico é a atividade da imaginação incluindo o presente como evidência de seu passado, foram apresentadas aos jovens portugueses e brasileiros questões diretamente relacionadas aos acontecimentos discutidos no ensino de história sobre o "descobrimento" do Brasil.

Em uma questão específica, foi admitida a possibilidade de os portugueses não terem sido os "descobridores" do Brasil. A partir disso, perguntamos aos alunos o que teria, então, acontecido ao Brasil.

A natureza do instrumento de pesquisa elaborado levou em consideração questões relativas à forma de aprendizagem da história na escola básica e, assim, baseamo-nos em Fosnot (1998a, p. 52), em sua argumentação de que:

0 desequilíbrio facilita a aprendizagem. Há que oferecer investigações estimulantes e abertas em contextos realistas e significativos, que permitam aos alunos explorarem e criarem um grande número de possibilidades, tanto afırmativas como contraditórias.

Fosnot (1998b) ainda afirma que a aprendizagem é vista como um processo autorregulador, que enfrenta o conflito entre modelos pessoais já existentes do mundo e novos insights discrepantes. Além disso, constrói novas representações e modelos da realidade, como um empreendimento humano de formação de significados com ferramentas e símbolos culturalmente desenvolvidos.

Uma das questões importantes a serem demonstradas neste estudo, principalmente no que diz respeito aos alunos brasileiros, é o fato de que as atuais abordagens pedagógicas têm sido criticadas por não desenvolverem nos alunos um sentido crítico que lhes permita tomar decisões fundamentadas sobre as respostas históricas.

Em muitos casos, no Brasil e em Portugal, o desenvolvimento da disciplina de história na educação básica é realizado por meio do trabalho com conteúdos substantivos. $\mathrm{Na}$ história ensinada, de forma geral, não há espaço para que os alunos emitam opiniões, tomem decisões, escolham caminhos ou levantem hipóteses. Aos alunos, na maior parte das intervenções pedagógicas em sala de aula, é permitido apenas repetir o ensinado, reproduzir o texto do livro ou da aula do professor.

Segundo a professora de um dos colégios onde a pesquisa foi realizada no Brasil, os alunos, quando solicitados a emitir opiniões ou apresentar uma narrativa livre sobre algum tema, demonstram muito sofrimento e preferem escrever apenas que não sabem ou não lembram nas questões propostas.

Nesse sentido, por meio da coleta e do estudo de dados empíricos, tentamos compreender as noções que os alunos constroem sobre a história, a partir no processo de aprendizagem na escola formal. É nosso interesse entender como se formam as ideias históricas dos alunos. Em primeiro lugar, porque só se pode mudar aquilo que se conhece e, em segundo lugar, para promover situações de ensino de história que desenvolvam a

3- Estudo financiado pelo CNPq com bolsa de pós-doutorado, em 2013. Financiamento 2014/2016 - Edital de Ciências Humanas/CNPq. 
consciência histórica e que não valorizem apenas a reprodução pouco refletida de temáticas curriculares. Assim, entende-se a consciência histórica como uma atitude de orientação de cada pessoa no seu tempo, sustentada pelo conhecimento da história. Segundo Rüsen (2001, p. 66):

A consciência histórica constitui-se mediante a operação, genérica e elementar da vida prática, do narrar, com a qual os homens orientam seu agir e sofrer no tempo. Mediante a narrativa histórica são formuladas representações da continuidade da evolução temporal dos homens e de seu mundo, instituidoras, por meio da memória, e inseridas, como determinação de sentido, no quadro de orientação da vida prática humana.

As ideias foram coletadas pela construção de narrativas dos alunos, entendendo a narrativa como expressão - sob qualquer formato - da compreensão histórica e os sentidos que lhe são atribuídos.

\section{Enquadramento teórico}

A investigação em educação histórica tem como objetivo entender as relações que alunos e professores estabelecem com os conceitos e as categorias históricas, sejam ideias substantivas ou de segunda ordem. Por conceitos substantivos podem ser entendidos os conteúdos da história, como, por exemplo, o conceito de industrialização, Renascimento, revolução. Quanto aos conceitos de segunda ordem, são aqueles que estão envolvidos em quaisquer que sejam os conteúdos a serem aprendidos, dentre os quais podemos citar noções temporais como continuidade, progresso, desenvolvimento, evolução, época, enfim, aqueles que se referem à natureza da história (LEE, 2001).

Para Rüsen (2001), a meta-história - os conceitos de segunda ordem - constitui uma reflexão sobre a natureza da história com base na história enquanto algo que ocorreu no passado. A história é um modo de lidar com o passado, de atribuir-lhe sentido com o propósito de orientar as pessoas no presente, na dimensão temporal de suas vidas. Também podemos afirmar que a meta-história contempla os princípios mentais que constituem o pensamento histórico. A educação histórica tem especial interesse na forma pela qual o trabalho com fontes, as estratégias de ensino, os materiais didáticos, os objetos históricos, entre outros, colaboram para a formação do pensamento histórico e da consciência histórica de alunos e de professores.

0 entendimento das relações que alunos e professores estabelecem com os conceitos e as categorias históricas tem sido alvo de várias pesquisas na área de educação histórica. Esses estudos visam compreender as ideias de crianças e jovens na perspectiva de que é possível a construção de ideias históricas gradualmente mais sofisticadas pelos alunos, no que diz respeito à natureza do conhecimento histórico (como, por exemplo, nas pesquisas de BARTON, 2001; WERTSCH, 2002; BARCA, 2011, 2007; SCHMIDT, 2008; GAG0, 2007; GEVAERD, 2009; ALVES, 2011).

\section{Enquadramento metodológico}


$\mathrm{Na}$ tentativa de entender as mensagens apresentadas nas narrativas dos alunos brasileiros e portugueses sobre as relações entre passado, presente e futuro, tentamos identificar tanto os conceitos epistemológicos quanto os substantivos presentes em suas narrativas sobre a história do Brasil em relação com a história de Portugal. Quando apresentam alguma homogeneidade transversal à maioria das narrativas específicas, indiciam identidades coletivas orientadas em determinado sentido.

Com esse propósito, realizamos um estudo de natureza essencialmente qualitativa (com abordagem quantitativa adicional), com alunos portugueses e brasileiros, sendo que os dados foram coletados no Brasil e em Portugal com alunos nas mesmas séries escolares.

As metodologias qualitativas de investigação constituem o conjunto de diretrizes que têm orientado as investigações científicas realizadas no campo da educação histórica. 0 foco da investigação é delimitado por questões relacionadas à cognição e à metacognição histórica, segundo Maria Auxiliadora Schmidt (2009). Do ponto de vista da cognição histórica situada, a explicação histórica constitui parte fundamental da narrativa histórica, processo inerente à natureza do próprio conhecimento histórico. Assim, a cognição histórica situada assume como pressuposto da aprendizagem a própria natureza narrativa da ciência da história.

As questões realizadas neste estudo permitiram evidenciar alguns elementos da perspectiva da cognição histórica dos alunos, o alcance dos conhecimentos prévios e a forma como eles tomam decisões sobre um conteúdo que precisa ser reescrito à luz dos seus saberes, neste caso, sobre a chegada dos portugueses ao Brasil.

\section{Participantes}

Para iniciar nossa investigação, aplicamos um questionário a 570 alunos no total, sendo 450 alunos de duas escolas da cidade de Londrina, Paraná, Brasil, e 120 alunos de duas escolas da região do Grande Porto, Portugal ${ }^{4}$.

No Brasil, o instrumento foi aplicado nas turmas do $6^{\circ}$ ao $9^{\circ}$ ano, com alunos de idades entre 12 e 15 anos, em duas escolas. Essas escolas se encontram na mesma região da cidade de Londrina, em bairros diferentes. Denominaremos, aqui, como Escola 1 e Escola 2, para evitar a identificação dos sujeitos e dos lugares. A Escola 1 fica em uma região de periferia com uma população de classe média baixa (sobretudo filhos de operários e prestadores de serviços). A Escola 2 está localizada no designado centro expandido e tem uma população de classe média baixa e classe média (filhos de comerciantes, comerciários, professores e profissionais liberais). Para a escolha das escolas brasileiras, levamos em

\footnotetext{
4- A seriação em Portugal se iguala a do Brasil no tempo destinado à educação básica (doze anos), mas difere na divisão dos tempos de estudo. No Brasil, a educação básica é dividida em três ciclos: cinco anos no ensino fundamental 1, quatro anos no ensino fundamental 2 e três anos no ensino médio. Em Portugal, a organização é a seguinte: $1^{\circ}$ ciclo: $1^{\circ}$ ano (6 de idade), $2^{\circ}, 3^{\circ}$ e $4^{\circ}$ (com exames de português e matemática, que valem 25\%); $2^{\circ}$ ciclo: $5^{\circ}, 6^{\circ}$ ano (com exames de português e matemática, que valem $25 \%$ ); $3^{\circ}$ ciclo: $7^{\circ}, 8^{\circ}$ e $9^{\circ}$ ano (com exames de português e matemática, que valem 25\%); ensino secundário, que é de caráter obrigatório: $10,11^{\circ}$ (com exames nas disciplinas que terminam nesse ano) e $12^{\circ}$ (com exames das disciplinas que terminam nesse ano). São doze anos obrigatórios atualmente.
} 
consideração os aspectos culturais dos alunos e a proximidade dos professores com projetos na Universidade Estadual de Londrina.

Para a escolha das escolas portuguesas também foi pensada a perspectiva da heterogeneidade do contexto cultural. Nesse caso, os alunos que participaram da pesquisa são do $6^{\circ}$ e $9^{\circ}$ anos, com idades entre 12 e 14 . Mesmo com turmas heterogêneas, essas escolas têm uma população semelhante à do Brasil no seu conjunto (filhos de funcionários públicos e trabalhadores). Denominaremos as escolas portuguesas de 3 e 4 .

No caso dos alunos brasileiros, no $6^{\circ}$ ano estavam estudando a Grécia Antiga e ainda não tinham estudado o conteúdo sobre história do Brasil. Os alunos do $9^{\circ}$ ano estavam estudando as Revoluções Burguesas, sendo que a história do Brasil já havia sido abordada no $6^{\circ}$ e $7^{\circ}$ anos. No que se refere aos alunos portugueses, no $6^{\circ}$ ano estudaram a história de Portugal e também as navegações portuguesas, e os alunos do $9^{\circ}$ ano, tais como os brasileiros, já haviam tido contato com o conteúdo em algum momento escolar.

\section{Instrumentos e procedimentos de aplicação}

Tendo como perspectiva os estudos de Chapman (2009), elaboramos um instrumento de pesquisa em que pudéssemos entender a progressão conceitual dos alunos a partir da possibilidade de pensarem a variação de perspectivas em história. As questões que constam do Quadro 1 fizeram parte do estudo principal. Apenas a última pergunta não fez parte do estudo aplicado em Portugal.

Quadro 1 - Questões colocadas aos alunos.

1) Se os portugueses não tivessem chegado ao Brasil em 1500, o que seria diferente e o que permaneceria da mesma forma na história do Brasil?

2) Qual a matéria mais importante sobre a história de Portugal/Brasil que você já estudou? Qual o período da história de Portugal/Brasil que você mais gosta de estudar? Qual o(a) maior herói/heroína da história portuguesa/brasileira? Justifique.

3) Imagine que você está na internet conversando com pessoas de vários países e precisa contar a história do Brasil que você conhece para o colega. Faça uma narrativa contando essa história para seu amigo.

*4) Complete a frase contando a história do Brasil até os dias atuais:

Em 1500, portugueses a bordo de três caravelas, comandadas por Pedro Álvares Cabral, chegaram à costa do que hoje chamamos de Brasil.

*Questão colocada apenas aos alunos brasileiros. Fonte: dados da pesquisa.

Nosso interesse na construção do instrumento de pesquisa se insere em duas problemáticas de caráter epistemológico. A primeira com relação aos conteúdos substantivos que dizem respeito à possibilidade de os alunos perceberem que a história não é determinada. Levamos em conta o desenvolvimento desse conteúdo em sala de aula de forma que, ao estudarem os conteúdos substantivos sobre o período, os alunos conseguissem estabelecer relações entre as grandes navegações e a possibilidade de 
outros países também chegarem ao continente, tendo como pressupostos o pensamento de Koselleck (2006) e de Hawthorn (1991) sobre possiveis anterioridades e posterioridades do acontecimento a conferirem sentidos ao passado.

Em segundo lugar, consideramos, nas escolhas argumentativas das narrativas dos alunos, as questões relacionadas à meta-história e à forma de explicação que os alunos encontrariam para justificar um não acontecimento histórico. Com relação a essa problemática (questão 1), indagamos quais fatores os alunos utilizariam para explicar o não acontecimento, quais fatores resultariam desse não acontecimento e quais as consequências que esse fato acarretaria historicamente. Nas questões seguintes, os alunos teriam necessariamente que fazer escolhas historiográficas e seleção de conteúdos substantivos para compor suas narrativas.

Segundo Mattozzi (1998, p. 24), devemos tomar consciência de que a história ensinada pode não ter qualquer eficácia, ou a sua eficácia pode ser contrariada pelas contra-histórias que circulam fora da escola. Acreditamos que a escola pode interferir nesse processo de forma poderosa, tomando como suporte metodológico no ensino de história o desenvolvimento das capacidades cognitivas da criança de pensar historicamente.

Mattozzi (1998, p. 29) ainda afirma que a escola deve formar personalidades cognitivas capazes de submeter a exame (historiográfico) a lógica das construções dos discursos sobre o passado. É a partir do desenvolvimento das estruturas de pensamento sobre o mundo sob uma perspectiva histórica que possibilitaremos aos alunos, desde as séries iniciais, uma formação histórica que fuja da simples preocupação conteudista nos currículos. Esse pensar historicamente está intimamente relacionado à complexidade da temporalidade histórica.

Neste artigo, selecionamos para discussão a análise das respostas à primeira pergunta fornecidas tanto por alunos portugueses como por alunos brasileiros do $6^{\circ}$ ano. Analisamos a forma como os alunos brasileiros e portugueses responderam ao desafio de pensar a história do Brasil sem a presença portuguesa no descobrimento. Pretendeu-se, ainda, nesse caso específico, perceber quais operações mentais os alunos movimentam em torno de uma questão de caráter hipotético sobre o passado.

Tendo como pressuposto, como afirma Dray (1980), que as causas de um acontecimento não são fatos objetivos e imutáveis à espera de serem descobertos, antes emergem dos pressupostos do julgamento histórico, da interpretação e do ponto de vista do historiador, tivemos como objetivo, portanto, mapear a relação que o aluno do ensino fundamental estabelece entre possíveis causas e consequências de um determinado acontecimento histórico, a partir da questão: se os portugueses não tivessem chegado ao Brasil em 1500, o que seria diferente e o que permaneceria da mesma forma na história do Brasil?

Sendo assim, podemos afirmar que a sugestão da narrativa, ao não focalizar a análise sobre um fato que realmente aconteceu, levou os alunos a terem que movimentar conhecimentos para além daqueles condicionados e materializados nos materiais didáticos. Nosso estudo levou em consideração investigações na área de educação histórica, que têm sugerido que os alunos dão sentido aos conteúdos históricos utilizando conceitos fornecidos pelas suas vivências na realidade atual. 
Outra relação diz respeito à contribuição da história para a educação e a formação do pensamento, que não está no conhecimento mecanizado ou na simples compreensão de situações do passado (lições a seguir ou a evitar), mas em um exercício de reflexão gradualmente objetivo e crítico, sobre diferentes ações, razões, motivos e interesses dos diversos agentes históricos (LEE, 2008).

\section{Análise de dados}

Para a análise indutiva dos dados relativos à questão proposta, consideramos as respostas dos alunos com relação aos conteúdos substantivos apresentados, e ainda outra com relação a um pensamento de segunda ordem. Quanto aos conceitos substantivos, podemos agrupar as respostas dos alunos brasileiros e portugueses da forma apresentada nos Quadros 2 e 3.

Quadro 2 - Conceitos substantivos apresentados por alunos brasileiros.

$$
\begin{aligned}
& \text { Manutenção do Brasil no estado de natureza intocável. } \\
& \text { Permanência da população como indígena. } \\
& \text { Ausência de tecnologia. } \\
& \text { Mudança na forma de ensinar história: diálogo passado e presente. } \\
& \text { Mudança na língua e ausência de país. }
\end{aligned}
$$

Fonte: dados da pesquisa.

Quadro 3 - Conceitos substantivos apresentados por alunos portugueses.

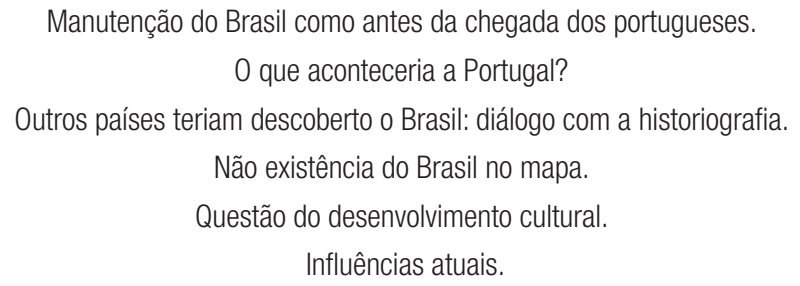

Fonte: dados da pesquisa.

Entre as ideias meta-históricas sugeridas nas respostas substantivas, sobressaem-se as que se relacionam com noções de mudança ou permanência e que foram agrupadas em três categorias: 1) paragem no tempo; 2) paragem no tempo e consequências para o presente; e 3) outros cenários possíveis.

Categoria 1: as respostas que consideram ausência de mudança e de tecnologia apontam, ao nível das noções meta-históricas ou de segunda ordem, para uma ideia de permanência ou de continuidade no caso da não ocorrência do evento consubstanciado pela chegada de Cabral ao Brasil. Há nessas respostas uma ideia de paralisação da história do Brasil, com um tempo intocado da natureza e da falta de tecnologia (avançada). Para 
uns, essa paragem no tempo significaria simplesmente uma melhor qualidade para os povos que aqui viviam. Exemplos de respostas de alunos brasileiros:

Não ficaria igual, pois existiriam muitas árvores, indígenas e se ninguém ainda descobriria, seria um país mais verde (natural).

Se os portugueses não tivessem chegado ao Brasil, nós não seríamos brancos, nós iríamos viver na floresta, em vez de casas, o ar seria um pouco mais limpo.

Quase tudo seria diferente se os portugueses não tivessem chegado ao Brasil, não teria tecnologia, cidades e pessoas como nós e os índios viveriam melhor sem a nossa chegada.

Para outros alunos, essa paragem no tempo é revestida de um sentido porventura ambivalente quanto à qualidade de vida:

Sim, seria diferente. Porque se os portugueses não tivessem chegado aqui nós ainda viveríamos com tangas e no meio do mato. 0 ouro e a prata seriam achados muito fácil e nós saberíamos lidar com as doenças mais conhecidas no Brasil. Permaneceria as guerras entre uma tribo e outra.

É difícil achar uma coisa que não foi mudada, a única coisa que eu acho seria a nossa fauna e flora diversa teria mais árvores e plantas também teria animais extintos, mas nenhum de nós teria nascido. Resumindo, se não fosse o Pedro Álvares Cabral ter errado a viagem o Brasil seria talvez uma grande selva.

Não ia ter tecnologia nem arma de fogo, ia ter mais árvores, não ia ter prédios, nada disso que tem agora ia ter.

Outros alunos, ainda, parecem atribuir um sentido negativo a tal situação de paragem, como em: "0 Brasil não teria essa tecnologia de hoje e nem teríamos grandes cidades".

Tal como para os alunos brasileiros, também para os portugueses existe um pensamento sem o descobrimento por Cabral aliado a um sentido de paralisação temporal do Brasil. Para uns, essa paralisação temporal não explicita uma carga valorativa: "Manutenção das florestas, dos indígenas"; "Permaneceria igual era, ou seja, indígena"; "Permaneceria da mesma forma - os animais e as plantas e permaneceriam mais escuras, pois eram índios”.

Para vários alunos portugueses, a exemplo de alguns alunos brasileiros, a ausência do descobrimento traria consequências positivas: "Ia permanecer como no início ainda teria mais índios, pois não teriam sido explorados de forma tão brutal"; "Ia permanecer igual com uma história menos dolorosa, teriam muito mais liberdade os índios, pois não seriam explorados pelos portugueses". 
Categoria 2: se a maior parte dos alunos, no Brasil ou em Portugal, fixou-se em uma simples ausência de mudança pelo fato de não ter ocorrido um determinado evento significativo (como se não pudesse haver outros fatores que conduzissem a outras consequências), alguns alunos apresentaram um pensamento ligado à emergência da conceitualização de mudança. Essa emergência da ideia de mudança é indiciada pela construção mental de um cenário alternativo em relação a situações do presente: diálogo passado e presente ou mudanças na forma de ensinar história.

Exemplos de respostas de alunos brasileiros:

Sim, a história do Brasil iria ser diferente porque os índios estariam na maioria das histórias brasileiras, mas eles não estão, porque os portugueses descobriram o Brasil, porque são de Portugal.

Seria diferente, mas não iríamos estudar sobre ele, pois eles não estariam nos livros, etc.

Sim, seria diferente, as pessoas não descobririam o Brasil, o Paraná não seria nada, as minas de ouro, ninguém descobriria as matas só teria índios e a gente não teria outros estados e não saberíamos outra língua.

Sim, diferente o Brasil não seria mais um país.

Exemplos de respostas de alunos portugueses:

Se os portugueses não tivessem chegado ao Brasil a língua seria totalmente diferente pois o Brasil teria sido colonizado por outros países como Inglaterra.

Se Portugal não tivesse chegado ao Brasil em 1500 os brasileiros não falavam a mesma língua, pois não tínhamos colonizado seu país. 0 resto da história do Brasil seria diferente pois sua língua e provavelmente sua cultura seria diferente.

Categoria 3: alguns poucos alunos concebem a mudança e avançam com cenários alternativos à história existente, como, por exemplo, a resposta de um aluno português, que problematiza consequências para o seu próprio país:

Se os portugueses não tivessem chegado ao Brasil, Portugal não conheceria o ouro, os índios e muito mais coisas. [...] E se Portugal não tivesse conhecido o Brasil o Rei não teria podido refugiar-se e talvez agora em 2013 Portugal seria um país francês.

$\mathrm{Na}$ resposta acima, a narrativa se volta para a história portuguesa dando um sentido não ao que aconteceria ao Brasil, mas sim ao que aconteceria a Portugal, o que é mais significativo para esse aluno. Notamos na narrativa uma possibilidade de diálogos alternativos entre passado, presente e futuro. Como afırma Rüsen (2010), a consciência histórica é uma combinação complexa que contém a apreensão do passado regulada pela necessidade de entender o presente e presumir o futuro. Dessa forma, o aluno se debruça 
em ir além de um passado fixo, estabelecendo cenários de relações explicativas com o presente e o futuro, no plano das possibilidades lógicas (mas não reais).

Em algumas narrativas, podemos perceber um diálogo mais avançado com a historiografia em termos de perspectiva de mudança e relação com evidências do presente, numa interação dinâmica entre tempos. Alguns alunos portugueses adiantam que outros países poderiam ter descoberto o Brasil, mas não indicam algum país específico, apenas sugerem numa narrativa aberta que, se não fossem os portugueses, poderia ser outro povo:

Podia ser outro país a encontrar o Brasil.

Acho que o Brasil seria dominado por outro país e iria conseguir também a independência.

O Brasil mais tarde iria ser descoberto, portanto o Brasil iria aparecer no mapa.

Se os portugueses não tivessem chegado ao Brasil, o Brasil tinha sido descoberto por outro país, esse país até podia não pertencer à união europeia.

Eu acho que se não tivéssemos chegado ao Brasil em 1500 o Brasil teria sido ocupado por outro povo qualquer.

Para além dos sentidos de mudança, precisamos, em nossa análise, levar em consideração as teias tensionadas de formação da identidade desses jovens, a qual é complexa, constituída por uma rede de pertenças, em que os sentimentos e ideias ligados a um povo se integram numa relação de consenso, tensão ou, por vezes, de conflito. Como afırma Rüsen (1993), a(s) identidade(s) é(são) alimentada(s) pelo saber histórico, mas também resultam de interesses práticos.

Entre os fatores que marcam as mensagens apresentadas pelos alunos portugueses e brasileiros está a forma de constituição do ensino de história ensinada, voltado ainda no século XXI para a formação de uma identidade nacional marcadamente oitocentista. Na questão meta-histórica, uma ideia partilhada por muitos alunos é que o passado é verdadeiro e imutável. Assim sendo, caso tivesse ocorrido de outra forma, hipoteticamente, não seria possível uma história, na medida em que o tempo ficaria paralisado (categoria 1 na análise).

0 que chama a atenção nas respostas de vários alunos é tanto o caráter estático da história, que se não fosse assim não seria outra, como a perspectiva, em alguns casos, de que se não fosse assim seria de outra forma sem qualquer mediação de dúvida ou pressuposições quanto ao futuro. No entanto, em algumas narrativas, podemos perceber a relação de mudança e de diálogo com o presente, no que tange à ideia de que poderia acontecer algo diferente no Brasil, e o país seria dominado por outros. 0 tempo verbal acompanha uma previsão de futuro hipotética que dependeria de diversos fatores para ser concretizada. Nesse sentido, a história está ainda por ser feita ou realizada e cabe a quem comenta apenas inferir possíveis futuros a partir da questão colocada.

$\mathrm{Na}$ análise, percebemos o uso de marcadores temporais pelos alunos portugueses, como séculos, anos, períodos, pois há uma preocupação em localizar temporalmente as narrativas. Isso não se mostra com os alunos brasileiros, os quais não estabelecem relações temporais para construções narrativas históricas. 
No caso do Brasil, isso pode ser creditado à forma de ensinar história nas escolas brasileiras no fim do século XX, que contrapôs uma história dita moderna e temática a uma história tradicional marcada por fatos, datas e locais. Esse contraponto, que tornou negativo o uso de datas, acabou por retirar de muitas das salas de aula - tanto no ensino básico como no universitário - a preocupação com a questão de localização temporal de temas históricos. 0 professor não podia se preocupar em exigir datas, nomes e locais dos alunos. Caso assim fosse, seria considerado tradicional, no sentido de ultrapassado.

A ideia de um não acontecimento dando um sentido provisório ao conhecimento histórico definitivo causou perplexidade nas conclusões históricas dos alunos. De certa forma, provocou neles um percurso desafiador, sem mapas de informação indicativos, seja o livro didático ou a fala do professor, em torno das possibilidades históricas que uma mudança de acontecimentos causaria ao fato histórico colocado.

\section{Reflexões preliminares sobre o estudo}

Propusemos aos alunos que respondessem a um argumento para a ideia de um percurso temporal que não aconteceu, fazendo com que pensassem a partir de uma questão hipotética, sem necessariamente terem como parâmetro uma evidência concreta. As respostas que obtivemos, em muitos casos, não progrediram em torno de uma interpretação e discussão de argumentos históricos, mas sim ficaram ligadas a uma ideia de verdade histórica estática e imutável. Nesse viés, nosso estudo se aproxima das reflexões de Chapman (2009, p. 162), quando argumenta em suas análises que considerou haver limitações na conceitualização da interpretação histórica dos participantes, os quais pareceram, em diversas tarefas, não dominar as ferramentas necessárias para dar sentido à história.

Os acontecimentos apreendidos são predeterminados e, assim, como não ocorreram do jeito que os alunos conhecem, não podiam ocorrer de outras formas. 0 livro didático, por sua vez, sustenta-se como veículo de transmissão de uma história verdadeira.

Se, como afirma Barca (2011), a compreensão do passado está relacionada ao desenvolvimento do pensamento histórico (ideias de segunda ordem) combinados com a necessidade de promoção de um quadro coerente (substantivo) do passado, que possibilite aos jovens uma orientação temporal consistente para suas vidas, o quadro que encontramos acaba por demonstrar que o ensino de história nas escolas pesquisadas ainda não está estruturado para esse desafio.

Outro ponto de reflexão que podemos inferir é a ideia de um mito fundador que se expressa na chegada dos portugueses ao Brasil e, como afirma Chaui (2000, p. 9), tal mito é "aquele que não cessa de encontrar novos meios para exprimir-se, novas linguagens, novos valores e ideias, de tal modo que, quanto mais parece ser outra coisa, tanto mais é a repetição de si mesmo". Estamos analisando as narrativas a partir de questões colocadas pela historiografia que trabalha o mito fundador, a natureza, o fato histórico. Nesse caso, a história escolar do Brasil não cessa de reiterar esse mito todos os anos em salas de aula por todo o país. É como se o Brasil estivesse desde sempre à espera de Pedro Álvares Cabral.

Também podemos afirmar, sobre os temas que formam o passado mítico da nação, segundo Vesentini (1984, p. 76), que: 
[...] resistem à crítica e continuam a reproduzir-se. Organizam-se como pequenos “nós", pontos centrais em torno dos quais todo um conjunto de temas passa a ser referido através dessa rede de relações, articulando vários temas de um nó, cada um deles torna-se definidor e periodizador.

Ademais, Vesentini coloca que o livro didático não cria tais temas, apenas os reproduz e, dessa forma, a escola no Brasil atualmente é responsável pela manutenção dessa maneira de aprender a história.

Outra análise preliminar de nosso trabalho indica que a concepção de ensino de história ainda hoje vigente em muitas salas de aula brasileiras, mais especificamente das escolas analisadas neste estudo, foi gerada no Brasil do fim do século XIX. Por exemplo, pensamos que a monografia premiada no concurso do Instituto Histórico Geográfico Brasileiro, Como escrever a história do Brasil, do botânico alemão Karl Philipp von Martius, definiu marcos para feitura dessa história, como o descobrimento do Brasil, a independência, todos alicerçados a partir de Portugal, tendo em vista que a nação brasileira deveria ser apresentada como fruto da expansão marítima.

Entendemos, nesse sentido, como Cercadillo (2004), que um ensino de história centrado na perspectiva dos conteúdos curriculares substantivos, sem discutir várias ideias de segunda ordem que lhes estão inerentes, impede níveis de conceituação mais sofisticados e possibilidades de visualização da progressão do pensamento histórico entre alunos em diferentes contextos de escolarização.

Nos estudos realizados no Brasil, percebemos algumas questões preocupantes no que tange ao ensino aprendizagem da história. Uma dessas questões diz respeito à dificuldade que os alunos apresentam em construir uma teia narrativa explicativa coerente sobre o passado (CAINELLI, 2011).

Nossos dados revelaram também que os alunos concebem os conteúdos de história e a forma como eles são ensinados de acordo com a história tradicional, de maneira cronológica e baseada em fatos importantes. Portanto, "entendem, equivocadamente, que otimizar o tempo em sala de aula significa priorizar a leitura e a explicação do professor sobre o capítulo do livro didático, seguindo-se à realização de exercícios” (CAIMI, 2006, p. 25).

Afırmamos, então, que no ensino de história na educação básica, em muitos casos, ainda se concretiza enquanto conhecimento histórico a perspectiva ranqueana do século XIX, em que o "fato histórico é o ponto de chegada e de partida" (MALERBA, 2011) e a história ensinada é centrada nos acontecimentos. Tal entendimento do fato se reflete principalmente quando imaginamos a necessidade de ensinar história a partir de um determinado evento localizado no tempo e no espaço, o que significaria que o evento ou o fato seria materializado concretamente. A forma de representação da história que se estabelece no livro didático utilizado pelo professor e, consequentemente, na forma como o professor ensina história, traduz-se naquilo que $\mathrm{H}$. White chama de história prefigurada, ou seja, a história ensinada na sala de aula está desde sempre já préformada (MALERBA, 2011).

Dessa forma, podemos afirmar que o ensino de história em sala de aula tende a narrar acontecimentos, como fatos pré-demarcados e, como Koselleck argumenta, o acontecimento precisa ser visto como modalidade temporal ou não se concretiza. Os alunos 
perdem com isso a dimensão que "só com o mínimo de anterioridade ou posteridade se consegue a unidade de sentido que forma um acontecimento a partir dos incidentes" (KOSELLECK, 1993, p. 142), sem preocupação de criar relações explicativas abertas.

Também Barton (2001) alerta que, em referência aos Estados Unidos, os educadores devem começar por ajudar os alunos a problematizarem o conhecimento histórico para que eles compreendam a necessidade da evidência, abordagem que deverá ser fundada no contato com todo o processo de pesquisa histórica.

Notamos, ainda, que os alunos questionados tanto em Portugal como no Brasil, em sua maioria, não se ancoram em evidências históricas para construir afırmações possíveis à situação histórica sugerida, e, sim, em uma história já determinada e conhecida que, se não acontece, não há outra a ser colocada no lugar, pois os alunos não consideram a movimentação de outros fatores. 0 passado está domesticado pela história factual sempre repetida.

\section{Referências}

ALVES, Ronaldo C. Aprender história com sentido para a vida: consciência histórica em estudantes brasileiros e portugueses. 2011. Tese (Doutorado em Educação) - Faculdade de Educação da Universidade de São Paulo, São Paulo, 2011.

BARCA, Isabel. Consciência histórica - teoria e práticas:as mensagens nucleares das narrativas dos jovens portugueses. Revista de Estudos Curriculares, Braga, v.4, n. 2, p. 195-208, 2007.

BARCA, Isabel. Educação histórica: vontades de mudança. Educar em Revista, Curitiba, n. 42, p. 59-71, 2011.

BARTON, Keith. Ideias das crianças acerca da mudança através dos tempos: resultados de investigação nos Estados Unidos e na Irlanda do Norte. In: BARCA, Isabel (Org.). Perspectivas em educação histórica: Actas das Primeiras Jornadas Internacionais de Educação Histórica. Braga: CEEP: Universidade do Minho, 2001. p. 55-68.

CAIMI, Flávia Eloisa. Por que os alunos (não) aprendem história? Reflexões sobre ensino, aprendizagem e formação de professores de história. Tempo, Niterói, v. 11, n. 21, p. 17-32, 2006.

CAINELLI, Marlene Rosa. Entre continuidades e rupturas: uma investigação sobre o ensino e aprendizagem da história na transição do quinto para o sexto ano do ensino fundamental. Educar em Revista, Curitiba, n. 42, p. 127-139, 2011.

CERCADILLO, Lis. Las ideas de los alumnos sobre lo que es verdad en historia. Enseñanza de las Ciencias Sociales, Barcelona, n. 3, p. 3-14, 2004.

CHAPMAN, Arthur. Towards an Interpretations Heuristic: a case study exploration of 16-19 year old students' ideas about explaining variations in historical accounts. 2009. PhD thesis (Doctor in Education) - Institute of Education, University of London, London, 2009.

CHAUl, Marilena. Brasil: mito fundador e sociedade autoritária. São Paulo: Fundação Perseu Abramo, 2000. 
COLLINGW00D, Robin George. A ideia da história. Lisboa: Presença, 1978.

DRAY, William. Philosophy of history. Englewood: Prentice-Hall, 1980.

FOSNOT, Catherine Twomey (Org.). Construtivismo: teoria, perspectivas e prática pedagógica. Porto Alegre: ArtMed, 1998b.

FOSNOT, Catherine Twomey. Construtivismo: uma teoria psicológica da aprendizagem. In: FOSNOT, Catherine Twomey (Org.). Construtivismo: teoria, perspectivas e prática. Porto Alegre: ArtMed, 1998a. p. 25-50.

FOSNOT, Catherine Twomey. Construtivismo: uma teoria psicológica da aprendizagem. In: FOSNOT, Catherine Twomey (Ed.). Construtivismo e educação: teoria, perspectivas e prática. Lisboa: Instituto Piaget, 1999. p. 23-58.

GAG0, Marília. Consciência histórica e narrativa na aula de história: concepções de professores. 2007. Tese (Doutorado em Educação) - Universidade do Minho, Braga, 2007.

GEVAERD, Rosi Terezinha Ferrarini. A narrativa histórica como uma maneira de ensinar e aprender história: 0 caso da história do Paraná. 2009. Tese (Doutorado em Educação) - Universidade Federal do Paraná, Curitiba, 2009.

HAWTHORN, Geoffrey. Plausible worlds. Cambridge: Cambridge University Press, 1991.

KOSELLECK, Reinhart. Futuro passado: contribuição à semântica dos tempos históricos. Tradução de Wilma Patrícia Maas e Carlos Almeida Pereira. Rio de Janeiro: Contraponto: PUC, 2006.

KOSELLECK, Reinhart. Futuro passado: para una semántica de los tiempos históricos. Barcelona: Paidós, 1993.

LEE, Peter. Educação histórica, consciência histórica e literária histórica. In: BARCA, Isabel (Org.). Estudos de consciência na Europa, América, Ásia e África: Actas das Sétimas Jornadas Internacionais de Educação Histórica. Braga: CIEd: Universidade do Minho, 2008. p.11-32.

LEE, Peter. Progressão da compreensão dos alunos em história. In: BARCA, Isabel (Org.). Perspectivas em educação histórica. Braga: Universidade do Minho, 2001. p. 13-27.

MALERBA, Jurandir. Ensaios: teoria, história e ciências sociais. Londrina: Eduel, 2011.

MATTOZZI, Ivo. A história ensinada: educação cívica, educação social ou formação cognitiva. 0 Estudo da História, Braga, n. 3, p. 11-25, 1998. Actas do congresso: 0 ensino de história: problemas da didáctica e do saber histórico.

RÜSEN, Jörn. 0 desenvolvimento da competência narrativa na aprendizagem histórica: uma hipótese ontogenética relativa à consciência moral. In: SCHMIDT, Maria Auxiliadora; BARCA, Isabel; MARTINS, Estevão de Rezende (Org.). Jörn Rüsen e o ensino de história. Curitiba: UFPR, 2010. p. 51-77. 
RÜSEN, Jörn. Razão histórica: teoria da história: os fundamentos da ciência histórica. Tradução de Estevão de Rezende Martins. Brasília, DF: Universidade de Brasília, 2001.

RUSEN, Jörn. The development of narrative competence in historical learning: an ontogenetic hypothesis concerning moral consciousness. In: DUVENAGE, Pieter (Ed.). Studies in metahistory. Pretoria: Human Sciences Research Council, 1993. p. 63-84.

SCHMIDT, Maria Auxiliadora. Cognição histórica situada: que aprendizagem histórica é esta? In: BARCA, Isabel; SCHMIDT, Maria Auxiliadora (Org.). Aprender história: perspectivas da educação histórica. ljuí: Unijuí, 2009. p. 21-51.

SCHMIDT, Maria Auxiliadora. Perspectivas da consciência histórica e da aprendizagem em narrativas de jovens brasileiros. Tempos Históricos, Cascavel, v. 12, n. 1, p. 81-96, 2008.

VESENTINI, Carlos Alberto. Escola e livro didático de história. In: SILVA, Marcos Antonio da (Org.). Repensando a história. Rio de Janeiro: Marco Zero, 1984. p. 69-80.

WERTSCH, James V. Voices of collective remembering. Cambridge: CUP, 2002.

Recebido em: 05.06.2016

Aprovado em: 02.02.2017

Marlene Cainelli é doutora em história social pela Universidade Federal do Paraná, realizou estágio de pós-doutorado em educação histórica na Universidade do Minho. É professora da Universidade Estadual de Londrina e do Programa de Mestrado e Doutorado em Educação e do Mestrado em História, e líder do Grupo de Pesquisa História e Ensino.

Isabel Barca é doutora em educação, professora com agregação na Universidade do Minho e professora do Mestrado e Doutorado em Educação da Universidade do Minho. 